\title{
Network crowdsourcing and youth extremism prevention: law enforcement agencies and civil society
}

\author{
Pavel Fantrov ${ }^{*}$, Vladimir Shinkaruk ${ }^{2}$, Wilhelm Guhl $^{3}$, Natalya Solovyeva ${ }^{4}$ \\ ${ }^{1}$ Universitskiy Prospekt, 100, Volgograd, Russia, pavelfantrov@volsu.ru \\ ${ }^{2}$ Universitskiy Prospekt, 100, Volgograd, Russia, shinkaruk@volsu.ru \\ ${ }^{3}$ Augsburg, Germany, gulyaich@yandex.ru \\ ${ }^{4}$ Universitskiy Prospekt, 100, Volgograd, Russia, solovieva_na@volsu.ru
}

\begin{abstract}
The fight against the manifestation of extremism among young people is an urgent problem that goes beyond law enforcement and requires a comprehensive socio-political solution. At the same time, preventive measures and technologies for the prevention of this negative phenomenon of public life play a significant role in countering extremism. The effective implementation of crowdsourcing network technologies unites national security entities for a coordinated solution of an urgent problem and helps to level the extremist threat. Their effectiveness should be measured based on the number of identified facts of an extremist orientation, and also the quality of leveling the negative consequences caused by extremist activity. To achieve the goal and objectives of the study, a system of scientific methods based on the systemic principle, the institutional approach, and the sociological method was used. All these methods made it possible to identify the importance of network crowdsourcing technologies for the prevention of extremism among the youth in the context of interaction between the state and citizens. When determining the effectiveness of crowdsourcing network technologies, the study evaluated the projects "Cibersquad", "MediaGuard" and "STOPTERROR", which participated in the prevention of extremism among young people. Largely due to their promotion, the level of extremist crime in 2019-2020 was reduced (compared to 2018). The article substantiates the effectiveness of crowdsourcing network technologies and concludes that their widespread adoption can "socialize" the system of preventing extremism among the youth, provided that not only government agencies, but also constructively-minded citizens' associations are its most important

actors.
\end{abstract}

\section{Introduction}

Involving citizens in preventing extremism among the youth should become an important trend in the development of partnerships between society and the state [1]. However, at present, there is a kind of "communicative failure" between society and the government, reinforcing the controversies and antagonisms of youth and power. So, as one of the manifestations of this is not only the growing disappointment of youth in the possibility of realizing their potential provided by the state but also the deepening split between various groups of Russian society, for example, the old federal elite and young regional-level leaders [2]. The growing aggravation of social contradictions becomes a significant factor in the radicalization of public sentiment. This is also reflected in the results of a sociological survey conducted by the Levada Center on September 26 - October 2, 2019. So, $53 \%$ of respondents between the ages of 18 and 24 want to leave Russia. In this regard, the issues of technological support for the systemic interaction of citizens' associations and state structures to level extremist sentiments among Russian youth are of particular relevance. Currently, there is a need to establish a productive interaction between the active forces of the community to develop young generation and its humanistic spiritual and moral values as a systemic factor in opposing extremist ideologies. The implementation of network crowdsourcing technologies can play a significant role in solving these pressing problems.

\section{Problem Statement}

To combat the manifestations of extremism, complex systematic work of citizens' associations and state structures is needed. Scientifically based methods are required to carry out the task. The relevance of the problem is determined: firstly, by the increased risks as a result of the development of some negative phenomena (social contradictions, nationalism, extremism, religious radicalism, legal nihilism, xenophobia, etc.) among the youth; secondly, by a change under the influence of globalization of the social space caused by the transition to the information society and the need to use modern

\footnotetext{
* Corresponding author: pavelfantrov@volsu.ru
} 
technologies for solving social problems; thirdly, by the needs of the society for sound scientific recommendations on the developing of technologies to solve acute social issues; fourthly, by the need to clarify and update the content of the concept of "extremism", which may be used incorrectly in the process of law enforcement.

\section{Research Questions}

- Identify controversies arising from the interaction of law enforcement agencies and civil society structures.

- To assess network crowdsourcing as a modern technology for the prevention of network extremism.

- Describe crowdsourcing projects implemented by the state and society in the context of the prevention of youth extremism in modern Russia.

- Justify the effectiveness of network crowdsourcing technologies for the prevention of youth extremism.

\section{Purpose of the Study}

To characterize the peculiarities of interaction between law enforcement agencies and civil society structures in the context of their implementation of network crowdsourcing technologies to prevent extremism in the youth environment.

\section{Research Methods}

The methodological basis of the study is a system of principles and methods of scientific knowledge that were used to identify the role of network crowdsourcing technologies implemented in the context of the prevention of extremism among young people. In the research process, the following scientific methods were used:

- general scientific (ascent from the abstract to the concrete, analysis, synthesis, induction, deduction, modeling, comparison, etc.);

- systemic - in assessing the interaction of state structures and citizens' associations, which are the main actors in the prevention of extremism;

- institutional, focused on the study of institutions that are subjects and objects of the implementation of crowdsourcing network technologies;

- sociological, allowing on the basis of quantitative and qualitative data to evaluate the effectiveness of crowdsourcing network technologies used to integrate the activities of constructive citizens and law enforcement agencies.

\section{Findings}

Due to their age-specific psychophysical and sociocultural characteristics, youth is objectively a necessary public resource for modernization changes in Russian society [3]. After all, it always strives for the new and unknown, often decisively breaking the prevailing foundations and conservative stereotypes of thinking. It is often cramped in the strict framework of social conventions and restrictions, which often leads to nihilism and breach of the peace. Manipulators of various kinds can easily drag young people into extremist activities due to its lack of great life experience [4]. In Russian society, there are several adverse social factors that contribute to the inclination of young people to deviant, socially dangerous activities. These, first of all, include excessive polarization of higher and lower social groups; cognitive dissonance caused by globalization; socio-economic problems determining the decline in the demand for the creative potential of youth; ideological pressure from radical public organizations; the slowness of the state apparatus in solving acute social problems and its use of outdated and ineffective technologies [5].

Unfortunately, in the 21 st century, such phenomena as xenophobia, nihilism, nationalist sentiments and extremism continued to develop. Their carriers began to widely use modern digital technologies to promote their views [6]. Social networks are increasingly used by supporters of extremism for the brainwashing of the public and its incline towards a deviant activity. The rapid development of information technology allows supporters of extremism to actively use social networks for disseminating illegal information and involving young people in ultra-radical and terrorist organizations. So, most extremist crimes in Russia are committed on the Internet, in 2018 they amounted to about $80 \%$ of the total number of such crimes. Of the 1,265 extremist crimes, more than $75 \%$ of those that were registered in the Russian Federation in 2018, were identified on VKontakte social network.

Modern electronic technologies that provide financing for criminal activities have become widely used by the criminal community. Thus, cryptocurrencies are gaining popularity, and allow the sender and receiver to interact in a qualitatively different way. Cryptocurrencies create great difficulties in identifying channels for financing extremist activities. Features of cryptocurrency encryption will allow achieving a high degree of anonymity of participants in financial transactions. As a result, this "innovative" nature eliminates all available measures to combat the financing of extremist organizations. According to experts, the current situation requires the introduction of appropriate amendments to international criminal law [7]. Given the current lack of any state-legal regulation of cryptocurrencies at the national level, it seems appropriate to unify international and national legislation governing payment services, electronic payment systems, and virtual currencies. One way to overcome these obstacles is to empower law enforcement agencies to obtain information on the legality of the movement of funds, their origin, on the property and property status of close relatives of persons who committed an extremist act, if there is reason to believe that this property was obtained as a result of criminal activity [8]. The use of modern information technologies in the consolidation of state structures and associations of citizens aimed at 
protecting national interests would help to solve these problems effectively.

Network crowdsourcing should be highlighted as one of the innovative and effective network technologies in the field of extremism prevention among the youth. According to A.I. Kurylenko, this means the transfer of some of the functions that the state previously performed to a certain circle of entities - representatives of civil society [9]. E.G. Smolina defines crowdsourcing in a slightly different way as "... the modern practice of solving professional problems by laypeople on the principle of "the whole world" based on an online platform" [10]. The attribution of only laypeople to the crowdsourcing entities seems to us not quite correct since professionals can also act in their capacity. Ya. A. Tsukanov even demonstrates a slight disregard for crowdsourcing, recognizing it as a "crowd": "... the very interpretation of crowdsourcing "leads" to the main character - the crowd, which exists within the framework of information and communication technologies with a high level of cooperation" [11]. If citizens demonstrate a "high level of cooperation", then this is no longer a crowd, but an informal association of citizens.

To implement network crowdsourcing in modern Russia, a system of horizontal public relations is gradually being created, and their importance is also recognized by the authorities. So, the President of the Russian Federation V.V. Putin expressed the view that it is necessary to make greater use of the so-called crowdsourcing, modern technology of public examination. Every Internet user can offer proposals and solutions within its framework. The introduction of crowdsourcing into law enforcement practices enhances national security [12].

In terms of efficiency of using resource and technological support for the joint activities of law enforcement bodies and civil society structures, network crowdsourcing technologies are the optimal mechanism for the prevention of extremism among the youth. They “... can predict opportunities important for the state and build strategic steps for their implementation" [13], and they can also involve a significant number of citizens in the process of implementing national security policies through "new media" and crowdsourcing projects. The development of network technologies as a resource for crowdsourcing technologies such as "Cibersquad", "MediaGuard", and "STOPTERROR" has shown their effectiveness in solving the problems of extremism among young people.

In recent years, Russia has seen a downward trend in the number of recorded crimes of an extremist nature. So, in $2019,56.9 \%$ less extremist crimes were recorded compared to 2018. These indicators are undoubtedly associated with the effective implementation of crowdsourcing network technologies. Law enforcement practice shows that the prevention of extremist crimes is the simplest and cheapest in terms of cost for eliminating the consequences of extremist crime, but at the same time, it is the most effective way to eradicate extremist sentiments from the minds of the younger generation.

As in 1960-70, the streets of Soviet cities, along with police officers, were patrolled by members of public order squad, and now, cyber squads are patrolling the great interwebs. The United Russia faction has prepared a bill on the creation of cyber forces in Russia, which, together with law enforcement agencies, will fight extremism on the network. The CyberSquad network crowdsourcing project, created by the Safe Internet League, has already been operating in the Russian Federation since 2011 and unites more than 20 thousand volunteers in 36 constituent entities of the Russian Federation; however, the activities of cyber-workers are not regulated at the federal legislative level. Citizens' associations can arbitrarily search for extremism on the net, but law enforcement officials are not required to take note of information received from cybercriminals. The activities of cyber-workers can be legalized in the future [14]; the bill is currently being finalized. Its significance is as follows: it is proposed to create cyberforces on the initiative of citizens who have expressed a desire to oppose the spread of illegal information on the Internet, in the form of a public organization, with notification to the relevant executive authority. It will be possible to join the ranks of cyber-volunteers freely at the age of 18. Undoubtedly, the approval of this bill will increase the effectiveness of the prevention of extremist activities carried out in the implementation of network crowdsourcing technologies by cyber squads and law enforcement agencies. Confirmation of this is the fact that over the past 5 years more than 10 thousand sites and pages on social networks have been blocked and hundreds of criminal cases have been initiated with the help of cyber soldiers.

A successful example of the fight against extremism among young people is the implementation by the Young Guard of United Russia (MGER) of the MediaGuard network crowdsourcing project, which has been operating since March 13, 2013. The goal of this project is to consolidate the efforts of MGER activists to identify online resources specializing in the distribution of illegal content. For example, in 2018, "MediaGuard" activists checked more than 50,000 materials. More than 5,000 Internet resources with illegal content were identified and blocked, and methodological recommendations "How to Avoid Getting Into the Hands of ISIS Recruiters" made on the Internet and educational institutions RF.

For a number of economic, political, cultural and historical reasons, the south of Russia is most prone to extremism. Therefore, for the subjects of the Southern Federal District (SFD), the priority area of ensuring national security is the fight against extremism, including the youth. According to the Secretary of the Security Council of Russia N.P. Patrushev, in the southern regions of Russia in January-August 2019, about 88 thousand websites with extremist and terrorist information were blocked. With more than 100 thousand network resources, illegal information has been deleted. In addition, about 460 thousand requests for the detection of unlawful information of an extremist and terrorist nature were processed, more than 50 thousand court decisions on the ban on its dissemination were executed. These facts indicate that the system of civic associations should be further developed as an important 
component of the fight against extremism among young people. And some progress has been achieved.

Since the fall of 2015, the Commission of the Public Chamber of the Russian Federation for the harmonization of interethnic and interreligious relations has been implementing the STOPTERROR network crowdsourcing project, in particular in the southern regions of the Russian Federation. It is organized to monitor the Internet space, including social networks, for the availability of information propagandizing extremism and inter-religious hatred. During the first 2 years of its work, the project coordinators received over 7000 citizens' applications with links to specific resources of illegal content, and more than a thousand of them were blocked. As rightly notes I.A. Bronnikov, “... network civic activism has significant potential for increasing the effectiveness of systemic dialogue practices between the state and civil society institutions" [15].

\section{Conclusion}

The authors conclude that the development of modern technologies should have a scientific basis, which allows analyzing extremist crimes, emerging law enforcement practices, proposals to improve legal regulation in this area, and also developing measures to eliminate social factors that are catalysts for extremist behavior.

The authors also conclude that with the active involvement of constructive citizens' associations in the process of preventing youth extremism, the potential of modern technologies as systemically important tools for maintaining the sustainable development of the Russian superethnos increases significantly. At present, for the effective interaction of the state and civil society in the context of the prevention of extremism among young people, the following conditions must be achieved: a powerful resource and technological base for the functioning of civil society institutions and mechanisms to ensure their "entry" into the national security system; coordination of priorities and consolidation of the parties based on patriotic values; raising the level of legal awareness and legal culture of the young generation.

The effectiveness of network crowdsourcing technologies lies in solving problems of information security (identifying and blocking extremist websites, disseminating information on the Internet to combat illegal content, etc.) by constructive associations of citizens. Crowdsourcing projects aimed at preventing and combating network extremism among young people ("Cyberdruzhina", "Media Guard" and "STOPTERROR") are being successfully implemented in Russia. The use of crowdsourcing technologies in public practice implies obtaining a relatively quick and expected result in the process of solving acute social problems. In modern realities, it is necessary to develop an algorithm and criteria for the use of these network technologies in the activities of government structures and associations of citizens, while not compromising the interests of the latter. Therefore, for their successful implementation, it is important to achieve partnerships between citizens' associations and state institutions, since the prevention of youth extremism is in the interests of both sides.

Thus, the introduction of network crowdsourcing technologies for the prevention of youth extremism can help mitigate risks and threats among the youth and is a positive factor in improving national security, creating healthy relationships in society and preventing the threat of the transformation of certain youth groups into the social base of terrorism. Their wider implementation can initiate the long-term trend of "socialization" of the national security system, when not only state structures, but also public organizations of patriotically inclined young citizens act as a system-forming component. For this, it is necessary to create a real system of cooperation between authorities and public organizations, when officials are not suspicious of a popular initiative. This is quite possible with the openness of state authorities and the wide informing of citizens about decisions being made to solve social problems.

\section{Acknowledgment}

The reported study was funded by RFBR, project number 20-011-00688 "Model for the prevention of extremism among the youth: integration of the activities of civic associations and law enforcement agencies in the context of legal socialization".

\section{References}

1. I.L. Morozov, PolitBook 1, 34-47 (2018)

2. S.Yu. Biryukov, M.V. Bobovkin, M.A. Shmatov, Legal Concept 2, 13-20 (2020)

3. O.A. Yakovleva, Legal Concept 2, 84-88 (2020)

4. V.N. Gulyaikhin, O.E. Andryushchenko, P.P. Fantrov, E.V. Galkina, Bulletin of Volgograd State University. Series 4: History. Regional studies. International relationships 2, 77-85 (2018)

5. I.L. Morozov, Questions of political science 5, 910917 (2019)

6. A.O. Inshakova, Legal Concept 2, 6-12 (2020)

7. A.Yu. Tutukov, A.G. Bondar, Problems of Economics and Legal Practice 5, 277-280 (2019)

8. P.P. Muraev, D.N. Yakovlev, V.V. Shalimova, Legal Concept 2, 43-49 (2020)

9. A.I. Kurylenko, Theory and Practice of Social Development 2, 15-17 (2016)

10. E.G. Smolina, Islamic Studies 4, 63-77 (2015)

11. Y.A. Tsukanov, Bulletin of Volga Institute of Management 3, 130-137 (2018)

12. P.P. Fantrov, V.M. Shinkaruk, Legal Concept 2, 33-38 (2018)

13. S.A. Pankratov, S.V. Shakarbieva, Bulletin of Saratov University. New series. Series: Sociology. Political science 3, 329-333 (2016) 
14. D.G. Kakhhorov, V.M. Abdrashitov, Sh.Kh.

Machidzoda, Legal Concept 2, 43-49 (2020)

15. I.A. Bronnikov, PolitBook 2, 6-24 (2019) 